\title{
Effects of pharmacist intervention on polypharmacy in patients with type 2 diabetes in Japan
}

\author{
Takeshi Horii ${ }^{1,2^{*}}$ and Koichiro Atsuda ${ }^{1}$
}

\begin{abstract}
Objective: Investigation of polypharmacy in patients with type 2 diabetes revealed that medications administered according to the patient's symptoms and complaints strongly contributed to polypharmacy. We explored the effects of clinical ward pharmacy service, which evaluated the need for symptomatic treatment, therefore minimizing polypharmacy by reducing inappropriate medications.

Results: The number of drugs (hospitalization vs. discharge: 9 [1-17] vs. $7[1-16], \mathrm{P}<0.001$ ) and rate of polypharmacy (hospitalization vs. discharge: $75.4 \%$ vs. $61.1 \%, P<0.001$ ) were significantly lower at discharge. Since hospital admission, the number of drugs increased $(n=6,11 \%)$, remained unchanged $(n=15,28 \%)$, decreased by 1 drug $(n=4,8 \%)$, decreased by 2 drugs $(n=3,6 \%)$, and decreased by more than 2 drugs $(n=25,47 \%)$. Daily drug costs were significantly reduced (hospitalization vs. discharge: $\$ 8.3$ vs. $\$ 6.1, P<0.001$ ).
\end{abstract}

Keywords: Polypharmacy, Type 2 diabetes, Pharmacy service

\section{Introduction}

In Japan, the number of patients with type 2 diabetes (T2DM) is steadily increasing [1]. Medication used for the management of diabetes and its complications (such as hyperglycemia, microvascular complications, pain, insomnia, and other symptoms) may improve target outcome but can also have side effects that lead to the addition of unnecessary medications to the treatment regimen [2]. We identified that this strongly contributes to polypharmacy (PP) in these patients, resulting in an increased risk of adverse drug reactions, drug interactions, and medication non-adherence [3-9]. Symptomatic treatment depends on the patient's symptoms and complaints, such as pain and insomnia, and strongly affects PP [10]. Although there is an urgent need to

\footnotetext{
*Correspondence: horiit@pharm.kitasato-u.ac.jp

${ }^{1}$ Pharmacy Practice and Science I, Research and Education Center for Clinical Pharmacy, Kitasato University School of Pharmacy, 1-15-1 Kitasato, Minami Ward, Sagamihara, Kanagawa 252-0375, Japan Full list of author information is available at the end of the article
}

prevent PP, none of the devised methods have been put into practice at many facilities.

After a patient's admission at the hospital, a clinical ward pharmacist evaluates inappropriate medications using a pharmaceutical approach and checks for PP. The clinical ward pharmacy service is effective in eliminating PP, as reported in the United States of America and in Europe [11-14]. But so far, no similar studies have been carried out in Japan. Therefore, we investigated how the clinical ward pharmacy service affects the rate of PP in T2DM in Japan.

\section{Main text \\ Methods}

An uncontrolled before-after study was conducted at the Shimokitazawa Hospital. The Shimokitazawa Hospital has outpatient and inpatient services, and specializes in the treatment of diabetes. In the hospital, certain wards are prepared to receive patients presenting with acute diabetes-related complications. The main responsibilities 
of the pharmacy service consist of controlling and dispensing medication, clinical data review, patient counseling, communication with healthcare professionals, and participation in ward rounds. We included patients who were newly admitted to the hospital in November 2017. The exclusion criteria were as follows: (1) type 1 diabetes, (2) age $<18$ years, and (3) clinical ward pharmacy service not implemented. We reviewed medical records to retrieve the patients' clinical information. Since PP is defined as taking six or more drugs, our primary outcome was the reduction in these medications. The secondary outcome was the change in daily drug costs from time of hospitalization to discharge.

Table 1 Patient characteristics

\begin{tabular}{|c|c|}
\hline & $\begin{array}{l}\text { Mean } \pm \text { S.D. } \\
\text { or median (min- } \\
\max ) \text { or } n(\%)\end{array}$ \\
\hline & Overall $n=53$ \\
\hline Male n (\%) & $27(50.9)$ \\
\hline Age (years) & $68.8 \pm 14.0$ \\
\hline HbA1c (\%) & $7.1 \pm 1.6$ \\
\hline BMI $\left(\mathrm{kg} / \mathrm{m}^{2}\right)$ & $22.2 \pm 4.5$ \\
\hline eGFR (mL/min/1.73 m²) & $71.9 \pm 64.1$ \\
\hline Diabetes duration (years) & $7.9 \pm 5.9$ \\
\hline Number of drugs & $9(1-17)$ \\
\hline Polypharmacy n (\%) & $40(75.4)$ \\
\hline Hospitalization days (days) & $17.2 \pm 2.5$ \\
\hline
\end{tabular}

Polypharmacy was defined as taking six or more drugs

$H b A 1 c$ hemoglobin A1c, BMI body mass index, eGFR estimated glomerular filtration rate
Normally distributed numerical data is presented as mean \pm standard deviation. Categorical variables were analyzed using Fisher's exact test and Chi square test and are expressed as absolute numbers or percentages. Differences were regarded as significant when $\mathrm{P}<0.05$. All statistical analyses were performed using the Stata software (version 10; Stata Corp, College Station, TX, USA). In this study, 1 dollar (\$) was considered as equivalent to 100 yen. This study was conducted in accordance with the ethical guidelines for medical and health research involving human subjects. The ethics board of the Kitasato University approved the study (Control number: 17078) and provided permission to review patient records and use the corresponding data.

\section{Results}

Table 1 shows the characteristics of 53 patients who met the selection criteria.

By comparing the number of drugs and PP rate at the time of hospitalization and discharge, it was possible to observe that both the number of drugs (hospitalization vs. discharge: 9 [1-17] vs. 7 [1-16], $\mathrm{P}<0.001)$ and $\mathrm{PP}$ rate (hospitalization vs. discharge: $75.4 \%$ vs. $61.1 \%, \mathrm{P}<0.001$ ) were significantly lower at discharge (Fig. 1).

Since hospital admission, the number of drugs increased $(n=6,11 \%)$, remained unchanged $(n=15$, $28 \%)$, decreased by 1 drug $(n=4,8 \%)$, decreased by 2 drugs $(n=3,6 \%)$, and decreased by more than 2 drugs $(n=25,47 \%)$. Daily drug costs were significantly reduced upon comparing cost on the day of hospital admission with that on the day of discharge (hospitalization vs. discharge: $\$ 8.3$ vs. $\$ 6.1, \mathrm{P}<0.001)$. We have also analyzed
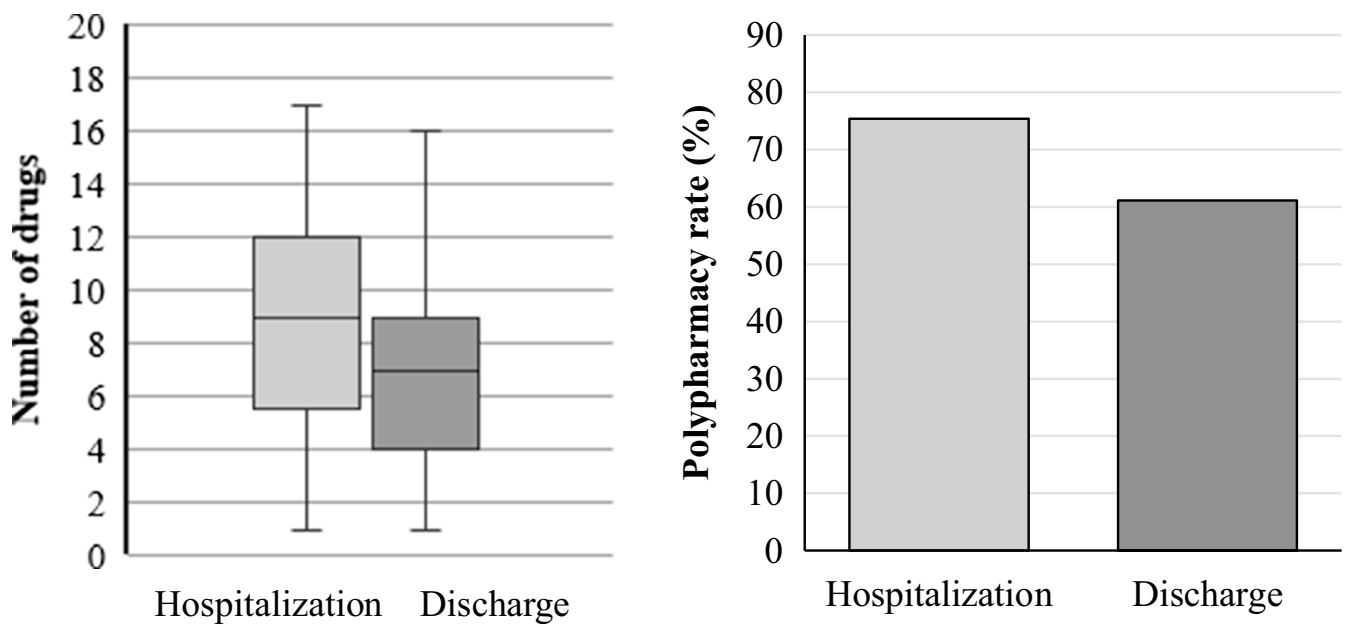

Fig. 1 Changes in number of drugs and polypharmacy rate The number of drugs (hospitalization vs. discharge: 9 [1-17] vs. 7 [1-16], P< 0.001) and PP rate (hospitalization vs. discharge: $75.4 \%$ vs. $61.1 \%, \mathrm{P}<0.001$ ) were significantly lower at discharge (Wilcoxon signed rank test) 
which drugs registered the most pronounced reduction in terms of frequency of use. In this aspect, acetaminophen was the drug whose frequency of use dropped the most, followed by angiotensin-converting-enzyme inhibitor and angiotensin II receptor blocker (Fig. 2).

\section{Discussion}

In our study, we determined factors that strongly affect PP through multivariate analysis. The results of this study suggest that by using the existing clinical ward pharmacy service, it is possible to lower the rate of PP and total drug costs per day, without a significant additional monetary investment in the care of patients.

In Japan, medical expenses are increasing not only for older adults, but also for diabetes patients. According to the statistics of the fiscal year 2019, Medical expenses are over $\$ 12$ billion in Japan [15]. Therefore, there is an urgent need to reduce medical costs, possibly by avoiding unnecessary medication and by reducing PP. However, in chronic diseases characterized by hyperglycemia and hypertension, it can take up to a year to determine the therapeutic effects of the medication, making it difficult to decide if the drugs should be discontinued during the patient's stay at the hospital. In contrast, the effects of drugs used for symptomatic treatment are fast-acting, allowing one to evaluate the effects of drug discontinuation in the short term. Medication used for symptomatic treatment is strongly responsible for PP in patients with T2DM and there are previous reports which show that drugs which have similar functions are frequently stopped [16]. Thus, we believe that active intervention

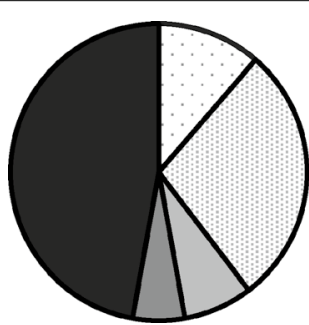

Increased

口Decreased by 1 drug $\square$ Decreased by 2 drugs
More than 2 drugs

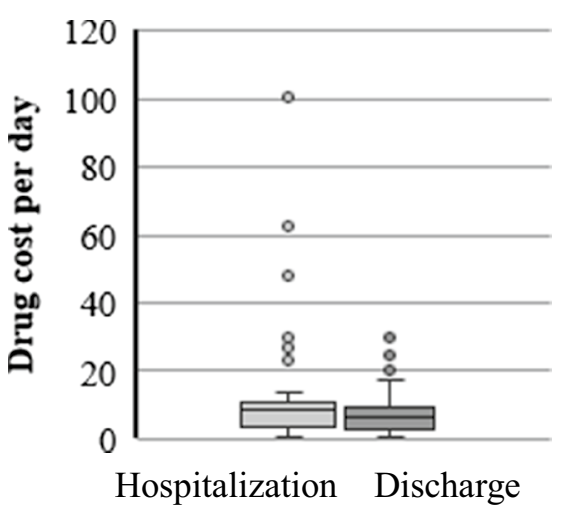

Hospitalization $\square$ Discharge

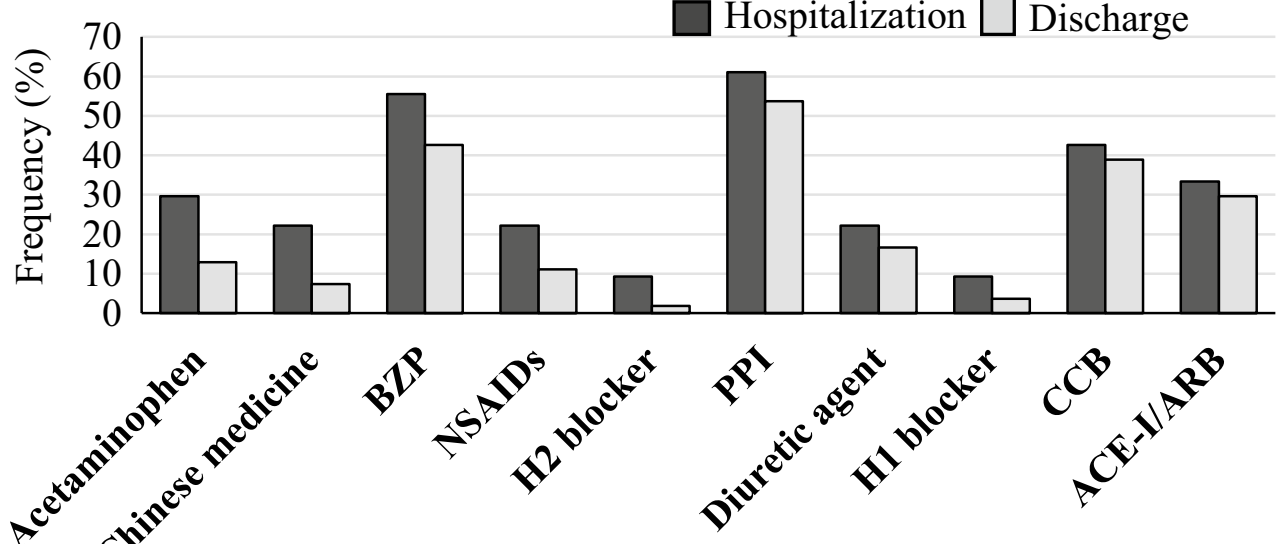

Fig. 2 Changes in the number of drugs and daily drug costs and top 10 drugs whose frequency of use changed significantly before and after hospitalization. Changes in the number of drugs since admission were increased (6 patients, $11 \%)$, unchanged ( $n=15,28 \%)$, decreased by 1 drug $(n=4,8 \%)$, decreased by 2 drugs $(n=3,6 \%)$, decreased by more than 2 drugs $(n=25,47 \%)$. Daily drug costs were significantly reduced when comparing hospital admission and discharge (hospitalization vs. discharge: 8.3 vs. $6.1, \mathrm{P}<0.001,1 \$=100$ yen, Wilcoxon signed rank test). ACE-/ Angiotensin-converting-enzyme inhibitor, ARB Angiotensin II receptor blocker, BZP Benzodiazepine, CCB Calcium channel blocker, NSAIDs Non-Steroidal Anti-Inflammatory Drugs, PPI Proton pump inhibitor 
in symptomatic treatment can be effective in addressing PP. Although we only observed a reduction in daily drug costs of about $\$ 1.7$, the reduction of PP per se helped improve the quality of life (QOL) by reducing the treatment burden.

Beers criteria and STPP criteria are used as a screening tool for potentially inappropriate medications (PIMs) in PP $[17,18]$. In Japan, the "Guidelines for medical treatment and its safety in the elderly" were proposed in 2005 by the Japan Geriatrics Society [19]. As these are screening tools for the older adults, they should not [10]. In our study, we extracted risk factors using multivariate analysis, which could prove useful for addressing PP in T2DM patients under 65 years of age.

Efforts to eliminate PPs include the use of screening tools such as the STOPP criteria and the establishment of specialized outpatient clinics with a multidisciplinary team consisting of doctors, nurses, and pharmacists focusing on the reduction of PP [20-24]. In a study conducted in Japan that extracted PIMs using the STOPP criteria and intervention of pharmacists, it was reported that $28.0 \%$ of the drugs that corresponded to STOPP criteria were changed [22]. On the other hand, all drugs changed in this study were done so according to the indication of pharmacists. For this reason, we do not recommend a change in treatment based exclusively on fixed criteria; symptoms differ between patients, and, therefore, the decision to discontinue a drug should be done on a case-by-case basis. In addition, while criteria and efforts to introduce new medical resources are effective in eliminating PP, at present, many facilities cannot enforce them. In fact, the New Health Care Fee, which is included among these new measures to stop PPs, covers only $16.5 \%$ of all hospitals [25]. Therefore, PP-reducing methods that take advantage of already-existing services and do not require any further resources should be considered. In our study, pharmacist interventions for PP were conducted for all ages. As a result, the PP rate was significantly reduced, and $53 \%$ of patients met the calculation requirement for the The New Health Care Fee by having reduced two or more PIMs.

\section{Conclusions}

We believe that the results of this study will foster further efforts in reducing PP in T2DM in Japan and Asia. By eliminating PP, medical costs are reduced, and the number of drugs taken is reduced, which increases patient satisfaction and contributes to improved treatment adherence. As a result, it is speculated that a reduction in PP has an impact on clinical outcomes such as QOL and Hemoglobin A1c levels. Based on the promising results of this pilot study, we are planning to carry out a larger intervention study in the future.

\section{Limitations}

There are several limitations in this study. First, we did not compare this study with cases where no intervention was performed, and we think it is necessary to examine the details of the effectiveness of this approach in the future. Finally, since interventions are centered on drugs for symptomatic treatment, there is still room for intervention in PIMs.

\section{Abbreviations}

ACE-I: Angiotensin-converting-enzyme inhibitor; ARB: Angiotensin II receptor blocker; PIMs: Potentially inappropriate medications; PP: Polypharmacy; QOL: Quality of life; T2DM: Type 2 diabetes.

\section{Acknowledgements}

Not applicable.

\section{Authors' contributions}

TH designed the study and wrote the initial draft of the manuscript. KA assisted in the preparation of the manuscript. All other authors have contributed to data collection and interpretation and have critically reviewed the manuscript. All authors agree to be accountable for all aspects of the work in ensuring that questions related to the accuracy or integrity of any part of the work are appropriately investigated and resolved. Both authors read and approved the final manuscript.

\section{Funding}

This research received no specific grant from any funding agency in the public, commercial, or not-for-profit sectors.

\section{Availability of data and materials}

The datasets used and/or analyzed during the study are available from the corresponding author on reasonable request.

\section{Ethics approval and consent to participate}

This study was conducted in accordance with the ethical guidelines for medical and health research involving human subjects. The ethics board of the T Kitasato University approved the study (Control number: 17078). The need for active informed consent was waived in detriment of the application of an opt-out method. Briefly, disclose the purpose of the study to participants, and given the opportunity to opt-out of being included in the research.

\section{Consent for publication}

Not applicable.

\section{Competing interests}

The authors declare that they have no competing interests.

\section{Author details}

${ }^{1}$ Pharmacy Practice and Science I, Research and Education Center for Clinical Pharmacy, Kitasato University School of Pharmacy, 1-15-1 Kitasato, Minami Ward, Sagamihara, Kanagawa 252-0375, Japan. ${ }^{2}$ Shimokitazawa Hospital, 2-8-16 Kitazawa, Setagaya Ward, Tokyo 155-0031, Japan.

Received: 24 December 2019 Accepted: 18 March 2020

Published online: 30 March 2020 


\section{References}

1. Ministry of Health, Labour and Welter Japan. 2019. https://www.mhlw. go.jp/bunya/kenkou/kenkou_eiyou_chousa.htm. Accessed 15 Jan 2020

2. Boyd CM, Darer J, Boult C, Fried LP, Boult L, Wu AW. Clinical practice guidelines and quality of care for older patients with multiple comorbid diseases: implications for pay for performance. JAMA. 2005;294:716-24.

3. Hajjar ER, Cafiero AC, Hanlon JT. Polypharmacy in elderly patients. Am J Geriatr Pharmacother. 2005;5:345-51.

4. Dumbreck S, Flynn A, Nairn M, Wilson M, Treweek S, Mercer SW, et al. Drug-disease and drug-drug interactions: systematic examination of recommendations in 12 UK national clinical guidelines. BMJ. 2015;350:1-8.

5. Hikaru K, Hitoshi K, Setsuko I, Katsuji N, Satoru M. The risk of adverse reaction in elderly patients undergoing polypharmacy. Jpn J Pharm Health Care Sci. 2003;29:100-6.

6. Campbell SE, Seymour DG, Primrose WR. A systematic literature review of factors affecting outcome in older medical patients admitted to hospital. Age Ageing. 2004;33:110-5

7. Espino DV, Bazaldua OV, Palmer RF, Mouton CP, Parchman ML, Miles TP, et al. Suboptimal medication use and mortality in an older adult community-based cohort: results from the Hispanic EPESE Study. J Gerontol A Biol Sci Med Sci. 2006;61:170-5.

8. Masoudi FA, Baillie CA, Wang Y, Bradford WD, Steiner JF, Havranek EP, et al. The complexity and cost of drug regimens of older patients hospitalized with heart failure in the United States, 1998-2001. Arch Intern Med. 2005;165:2069-76.

9. Cahir C, Fahey T, Teeling M, Teljeur C, Feely J, Bennett K. Potentially inappropriate prescribing and cost outcomes for older people: a national population study. Br J Clin Pharmacol. 2010;69:543-52.

10. Horii T, Kabeya Y, Shimizu J, Tomita M. Study on risk of polypharmacy caused by diabetes. Jap J Pharm Diabetes. 2017;6:179-87.

11. Peterson JF, Kuperman GJ, Shek C, Patel M, Avorn J, Bates DW. Guided prescription of psychotropic medications for geriatric inpatients. Arch Intern Med. 2005;165:802-7.

12. Ruhland DJ, Bellone JM, Wilkes E. Implementation and assessment of an ambulatory prescribing guidance tool to improve patient safety in the geriatric population. Consult Pharm. 2017;32:169-74.

13. Mattison ML, Afonso KA, Ngo LH, Mukamal KJ. Preventing potentially inappropriate medication use in hospitalized older patients with a computerized provider order entry warning system. Arch Intern Med. 2010;170:1331-6.

14. Lester PE, Rios-Rojas L, Islam S, Fazzari MJ, Gomolin IH. Impact of computerized physician order entry alerts on prescribing in older patients. Drugs Aging. 2015;32:227-33.
15. Ministry of Health, labour and welter japan, estimates of national medical care expenditure. 2018. https://www.mhlw.go.jp/english/database/dbhss/enmce_2017.html. Accessed 15 Jan 2020.

16. Wang HY, Chan AL, Chen MT, Liao CH, Tian YF. Effects of pharmaceutical care intervention by clinical pharmacists in renal transplant clinics. Transplant Proc. 2008;40:2319-23.

17. American Geriatrics Society. Beers criteria update expert panel American Geriatrics Society updated beers criteria for potentially inappropriate medication use in older adults. J Am Geriatr Soc. 2012;60:616-31.

18. O'Mahony D, O'Sullivan D, Byrne S, O'Connor MN, Ryan C, Gallagher P. STOPP/START criteria for potentially inappropriate prescribing in older people: version 2. Age Ageing. 2015;44:213-8.

19. Kojima T, Mizukami K, Tomita N, Arai H, Ohrui T, Eto M, et al. Screening tool for older persons' appropriate prescriptions in Japanese: report of the Japan geriatrics society working group on "guidelines for medical treatment and its safety in the elderly". Geriatr Gerontol Int. 2016;16:983-1001.

20. Hamano J, Tokuda Y. Inappropriate prescribing among elderly home care patients in Japan: prevalence and risk factors. J Prim Care Community Health. 2014;5:90-6.

21. Amano J, Ozone S, Tokuda Y. A comparison of estimated drug costs of potentially inappropriate medications between older patients receiving nurse home visit services and patients receiving pharmacist home visit services: a cross-sectional and propensity score analysis. BMC Health Serv Res. 2015:15:1-9.

22. Fumie O, Takeshi K, Atsushi U, Asuka T, Yuko A, Kazuhiro Y, et al. Pharmaceutical intervention to manage polypharmacy in elderly patients based on STOPP criteria. Iryo yakugaku. 2016:42:78-86.

23. Pyszka LL, Seys Ranola TM, Milhans SM. Identification of inappropriate prescribing in geriatrics at a Veterans Affairs hospital using STOPP/START screening tools. Consult Pharm. 2010;25:365-73.

24. Liu CL, Peng LN, Chen YT, Lin MH, Liu LK, Chen LK. Potentially inappropriate prescribing (IP) for elderly medical inpatients in Taiwan: a hospitalbased study. Arch Gerontol Geriatr. 2012;55:148-51.

25. Ministry of Health, Labour and Welter Japan. https://www.mhlw.go.jp/ file/05-Shingikai-12404000-Hokenkyoku-Iryouka/0000188847.pdf. Accessed 15 Jan 2020

\section{Publisher's Note}

Springer Nature remains neutral with regard to jurisdictional claims in published maps and institutional affiliations.
Ready to submit your research? Choose BMC and benefit from:

- fast, convenient online submission

- thorough peer review by experienced researchers in your field

- rapid publication on acceptance

- support for research data, including large and complex data types

- gold Open Access which fosters wider collaboration and increased citations

- maximum visibility for your research: over $100 \mathrm{M}$ website views per year

At BMC, research is always in progress.

Learn more biomedcentral.com/submissions 